\title{
The coevolution of building nests on the ground and domed nests in Timaliidae
}

\author{
Author(s): Zachary J. Hall, Sally E. Street, Sam Auty, and Susan D. Healy \\ Source: The Auk, 132(3):584-593. \\ Published By: The American Ornithologists' Union \\ DOI: http://dx.doi.org/10.1642/AUK-15-23.1 \\ URL: http://www.bioone.org/doi/full/10.1642/AUK-15-23.1
}

BioOne (www.bioone.org) is a nonprofit, online aggregation of core research in the biological, ecological, and environmental sciences. BioOne provides a sustainable online platform for over 170 journals and books published by nonprofit societies, associations, museums, institutions, and presses.

Your use of this PDF, the BioOne Web site, and all posted and associated content indicates your acceptance of BioOne's Terms of Use, available at www.bioone.org/page/terms_of_use.

Usage of BioOne content is strictly limited to personal, educational, and non-commercial use. Commercial inquiries or rights and permissions requests should be directed to the individual publisher as copyright holder. 


\title{
The coevolution of building nests on the ground and domed nests in Timaliidae
}

\author{
Zachary J. Hall, ${ }^{\text {a* }}$ Sally E. Street, Sam Auty, and Susan D. Healy \\ School of Biology, University of St. Andrews, St. Andrews, Scotland, UK \\ ${ }^{a}$ Current address: Cell \& Systems Biology Department, University of Toronto, St. George Campus, Toronto, Ontario, Canada \\ * Corresponding author: zach.hall@utoronto.ca
}

Submitted February 3, 2015; Accepted February 23, 2015; Published May 6, 2015

\begin{abstract}
Despite the accumulation of structural descriptions of bird nests and considerable diversity in these structures across species, we know little about why birds build the nests that they do. Here we used phylogenetic comparative analyses to test one suggested explanation, specifically for Old World babblers (Timaliidae): that building a domed nest coevolved with building a nest on the ground. We show that babblers that build domed nests build them at a lower height than do babblers that build cup-shaped nests, and that in this radiation the evolution of domed nests depended on the transition to building a nest on the ground. Our results are consistent with the hypothesis that babblers add a roof to the nest in order to confer protection against increased predation risk on the ground. We believe that this is the first formal identification of evolutionary pathways that have led to the diversity in nest structure and location that we see today.
\end{abstract}

Keywords: nest structure evolution, nest height evolution, nest-building behavior, domed nests, Old World babblers, Timaliidae

\section{Coevolución de la construcción de nidos en el suelo y nidos abovedados en Timaliidae \\ RESUMEN}

A pesar de la gran cantidad de descripciones de la estructura de los nidos de aves y de la considerable diversidad de estas estructuras, sabemos poco de por qué las aves construyen los nidos que construyen. Aquí empleamos un análisis filogenético comparativo para evaluar una posible explicación, específicamente para los Timaliidae: que la construcción de un nido en forma abovedada co-evolucionó con la construcción de un nido en el suelo. Mostramos que las especies que construyen nidos abovedados los construyen a menor altura que las especies que construyen nidos en forma de taza y que en esta radiación la evolución de los nidos abovedados dependió de transiciones para construir un nido en el suelo. Nuestros resultados son consistentes con la hipótesis de que las especies de Timaliidae agregan un techo al nido para brindarle protección de la mayor depredación que sufren en el suelo. Creemos que esta es la primera identificación formal de caminos evolutivos que han llevado a la diversidad de estructuras de nido y emplazamiento que vemos hoy.

Palabras clave: comportamiento de construcción del nido, evolución de las estructuras del nido, evolución de las alturas del nido, nidos abovedados, Timaliidae

\section{INTRODUCTION}

The tremendous diversity in avian nest structure has long been documented and celebrated. For example, in The Jungle Book, Rudyard Kipling (1899) describes nest building by the Common Tailorbird (Orthotomus sutorius), which stitches leaves together to form a deep cup. This structural diversity ranges from the simple stick platform of the Common Wood-Pigeon (Columba palumbus) to the intricate woven hanging nest of the Southern MaskedWeaver (Ploceus velatus) and it has been suggested that flexible nest-building behavior, alongside a small body and flight, was one of the key traits that enabled the adaptive radiation of passerines (Collias 1997). However, despite the accumulation of descriptions of nest structure for thousands of bird species (e.g., Collar and Robson 2007), together with an increasing focus on elucidating the structural properties of nests (Heenan and Seymour 2011, 2012), causes of intraspecific variation in nest structure (Deeming et al. 2012, Mainwaring et al. 2014), and the learning mechanisms and neural substrates associated with nest building (Muth and Healy 2011, 2012, 2014, Hoi et al. 
2012, Hall et al. 2013, 2014, Muth et al. 2013), we still know little of what shapes interspecific variation in the nest structure itself.

To date, studies on the evolution of nest structures have been focused on mapping the variation in structure onto contemporaneous phylogenies to describe evolutionary shifts in those structures (Winkler and Sheldon 1993, Eberhard 1998, Irestedt et al. 2006). Although this work has suggested roles for selection pressures, such as nestsite competition, in driving the variation in the nests that birds build, neither the coevolution of nest structure with these factors nor the influences that these factors might have had on nest traits such as nest location and structure have been tested. Here, we take advantage of recent avian phylogenetic reconstructions at both class (Jetz et al. 2012) and family (Moyle et al. 2012) levels and a simple nest categorization scheme based on structural complexity (Hall et al. 2013) to formally test one specific hypothesis regarding the evolutionary forces affecting nest-building behavior proposed by Collias (1997): that the construction of domed nests on the ground depended on the evolution of building a nest on the ground. In these clades, Collias (1997) suggested that ancestral species built open, cupshaped nests off the ground and that competition for limited nest sites off the ground favored construction of nests nearer to the ground, eventually leading to birds building nests on the ground. Collias (1997) argued that, because open-cup nests built nearer to the ground are thought to be susceptible to greater predation pressure from ground predators than are enclosed, domed nests (Linder and Bollinger 1995), an initial shift to building a nest on the ground should, therefore, be followed by the building of a domed nest to confer protection against this increased predation risk.

In his original proposal, Collias (1997) supported his hypothesis with data on Old World babblers (Timaliidae) from India, which build either cup- or dome-shaped nests. He reported that the majority of cup nest-building babblers built nests off the ground, whereas the majority of domed nest-building babblers built nests on the ground. Plausible though this hypothesis was, because Collias (1997) could not incorporate any information on phylogenetic relatedness of the sampled species, he could not formally investigate the potential coevolution of building domed nests with building nests on the ground, or the likely ancestral state or evolutionary transitions in nest structure and location in this clade. Here we investigate the coevolution of nest building on the ground and the building of a domed nest in the Timaliidae using a large species sample and phylogenetically informed statistical analyses to elucidate the evolutionary history of nest structure and location in this family.

If increasing proximity of a nest to the ground increases predation risk and building a domed nest confers increased protection from that risk, as Collias (1997) suggested, then those species that build domed nests should build their nests closer to the ground than do cup nest-building species. Furthermore, to determine whether building on the ground coevolved with the building of a domed nest, we carried out phylogenetic analyses of trait coevolution, including an ancestral state reconstruction and order of evolution analysis, to investigate the ancestral state of nest structure and location and to test whether coevolution was more likely to occur first through changes in nest height, as predicted by Collias (1997), or by changes in nest structure. As changes in nest location within an individual bird's lifetime have been reported (e.g., Marzluff 1998), whereas flexibility in nest structure is observed less often, we predicted that transitions would be more likely to occur first through changes in nest height, rather than nest structure.

\section{METHODS}

\section{Collection of Nest Data}

We gathered descriptions from previously published sources of the species-typical nest structure and of the lowest height of nests built by 155 species within Timaliidae (Collar and Robson 2007). We excluded species that were not included in the phylogenies used in our analyses (Jetz et al. [2012]: final $n=97$; Moyle et al. [2012]: final $n=91$; see below). We categorized nest structures as either cup or domed using the nest classification scheme described by Hall et al. (2013): Both cup and domed nests are characterized by a nest floor and surrounding walls created during construction. Domed nests, however, also have a roof.

In addition to nest structure, we recorded the lowest height at which nests were built. We used the lowest reported nest height because selection pressure exerted by ground predators should be greatest at the lowest height at which a nest is built. Whenever nests were described as being placed on the ground, we entered nest height as $0 \mathrm{~m}$. Nest structure and height data for species included in this study are summarized in Figure 1 and Supplementary Material Table S1.

\section{Phylogenetic Comparative Statistical Methods}

For all of the following phylogenetic comparative statistical analyses, we used Bayesian Markov chain Monte Carlo (MCMC) methods in order to estimate posterior probability distributions for model parameters (Pagel and Meade 2006), using the program BayesTraits (Pagel et al. 2004).

We ran all of our analyses on: (1) a posterior sample of 3,000 dated phylogenies from a recent global, class-wide Bayesian estimation for birds based on existing taxonomic and genetic data (Jetz et al. 2012; http://birdtree.org/); and (2) a single dated phylogeny from a family-specific 

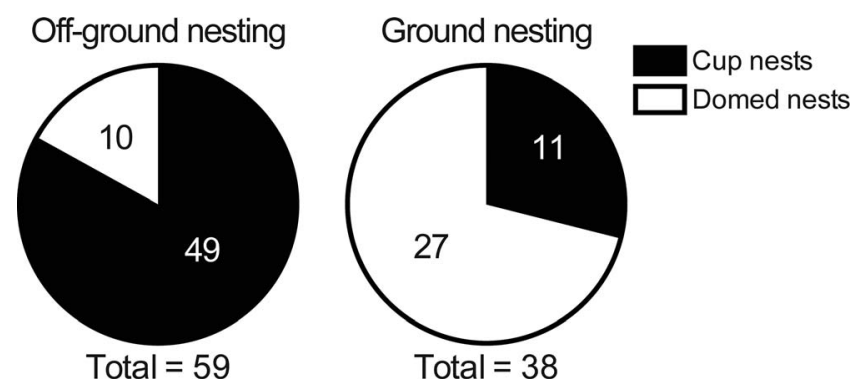

FIGURE 1. Classification of nest height and nest structure for the 97 species of Old World babbler (Timaliidae) included in this study. Numbers within segments of the pie chart correspond to the number of species building either cup nests (black) or domed nests (white).

reconstruction based on a newly assembled genetic dataset (Moyle et al. 2012). While the Jetz et al. (2012) reconstruction offered the advantage of allowing our analyses to account for phylogenetic uncertainty, the Moyle et al. (2012) analyses potentially provided a more robust phylogenetic estimation for the babblers due to the authors' use of solely molecular data and the inclusion of more species. We used a version of the Jetz et al. (2012) phylogenies built only from genetic data after the use of a taxonomic 'backbone' (Hackett et al. 2008). We used an ultrametric version of the Moyle et al. (2012) tree obtained from the lead author by request. Our phylogenetic comparative analyses required trees in which each tip was represented by a single species; however, the Moyle et al. (2012) tree originally included species with multiple individuals (total $n=292$ ). In order to be able to run comparative analyses on the Moyle et al. (2012) tree, we trimmed duplicate individuals where species had been reconstructed as monophyletic, and removed 10 paraphyletic species due to uncertain phylogenetic placement (remaining $n=181$ species after pruning duplicates; final $n$ $=91$ after matching species to data). A maximum clade credibility phylogeny from the Jetz et al. (2012) posterior sample of phylogenies is presented in Figure 2. Full model parameters for all phylogenetic models run in this study are summarized in Supplementary Material Table S2.

Height from the ground of cup vs. domed nests. We transformed nest height data using a $\log (x+1)$ transformation and compared these heights as a continuous variable between species building cup and domed nests using the phylogenetic generalized least squares regression (PGLS) approach, which incorporates phylogenetic relatedness into the error term of regression models (Grafen 1989, Pagel et al. 2004). Nest structure was included as an independent factor on 2 levels ('cup' and 'domed', where cup was the reference level). We used MCMC methods to estimate posterior probability distributions for regression coefficients $(\beta)$ and phylogenetic signal ( $\lambda$; Grafen 1989). We ran MCMC chains for PGLS analyses for 1 million iterations, sampling every 100 generations, with a burn-in period of 50,000 iterations. We used uniform priors (range: $-100,100)$ for all parameters.

Prior to analyses, we specified that where $\geq 95 \%$ of the posterior probability distribution of regression coefficients $(\beta)$ was in the predicted direction (negative, following the prediction that domed nests are built at lower heights than cup nests; this result is presented as " $\% \beta<0$ "), we would conclude that there was 'strong evidence' for the predicted relationship (e.g., Ross et al. 2012). We also report the mean $\lambda$ from the posterior probability distributions, where 0 and 1 indicate minimal and maximal phylogenetic signal, respectively.

Coevolution of nest height and structure. To investigate possible coevolution of nest height and nest structure, we used phylogenetic comparative statistical methods for detecting coevolution of discrete character traits (Pagel and Meade 2006). This approach uses continuous-time Markov models to estimate up to 8 transition rates between states of 2 binary traits. We converted nest height into a binary trait by coding it on 2 levels: 'ground, where nest height was $0 \mathrm{~m}$; and 'offground,' where nest height was $>0 \mathrm{~m}$. Nest structure was coded as before (cup or domed). For these 'discrete' analyses (models depicted in Figure 3), we ran chains for 100 million iterations, sampling every 5,000 generations, with a burn-in period of 50,000 iterations, using exponential hyperprior distributions (range: 0,5 ) for all parameters.

To compare models in which nest height and nest structure evolved dependently and independently of one another, we first used the reversible jump (RJ) MCMC approach, which estimates transition rates while simultaneously selecting the best-fitting model of evolutionary change by visiting models in proportion to their posterior probabilities (Pagel and Meade 2006). In the dependent RJ model (Figure 3A), transition rates for each character (denoted as $q_{i j}$, where $q$ characterizes the transition rate from one combination of nest height and structure $[i]$ to another nest height and structure state combination $[j]$ ) are permitted to depend on the state of the other character. In our dependent RJ model, specifically, transition rates between nest heights (ground and off-ground) could differ depending on nest structure built (cup and domed) and vice versa (i.e. in Figure 3A: $q_{12} \neq q_{34}, q_{13} \neq q_{24}, q_{43} \neq q_{21}$, and $q_{42} \neq q_{31}$ ). We compared this model to an independent RJ model (not shown) in which nest height and structure evolved independently and transition rates between nest heights were equal regardless of nest structure and vice versa (i.e. in Figure 3A: $q_{12}=q_{34}, q_{21}=q_{43}, q_{13}=q_{24}$, and $q_{31}=q_{42}$ ). If nest height and nest structure coevolved in Timaliidae, the dependent RJ model would be favored over our independent RJ model. If the dependent RJ model were favored, we would examine the mean transition rates 


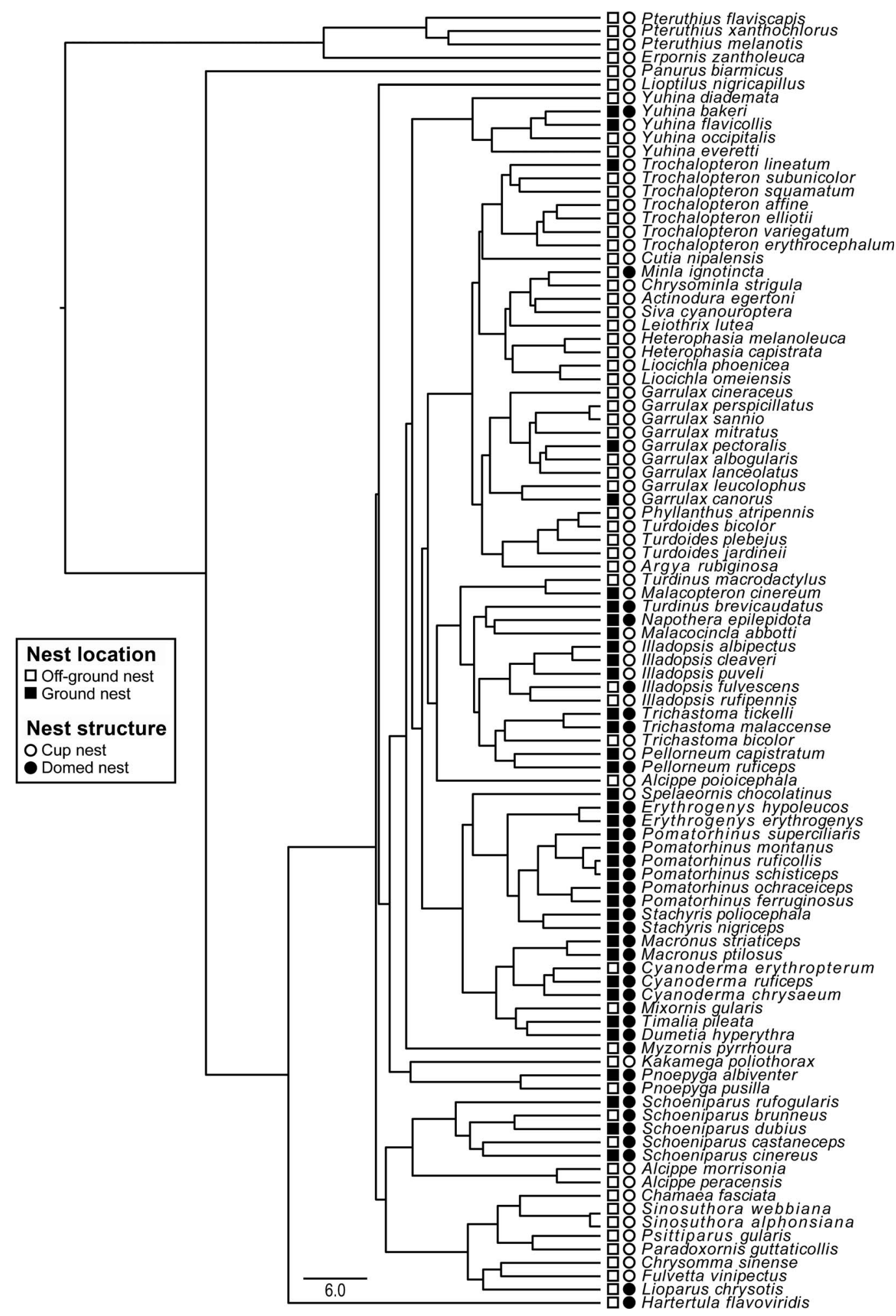

FIGURE 2. A maximum clade credibility phylogeny of Timaliidae species used in this study. Species-typical nest location (ground or off-ground) and nest structure (cup or domed) are shown before each species' scientific name. This maximum clade credibility phylogeny was constructed from a Bayesian posterior sample of 3,000 phylogenies from Jetz et al. (2012), which was constructed using genetic data only and a 'backbone' family estimation by Hackett et al. (2008). Scale bar represents 6 mya (Jetz et al. 2012). 

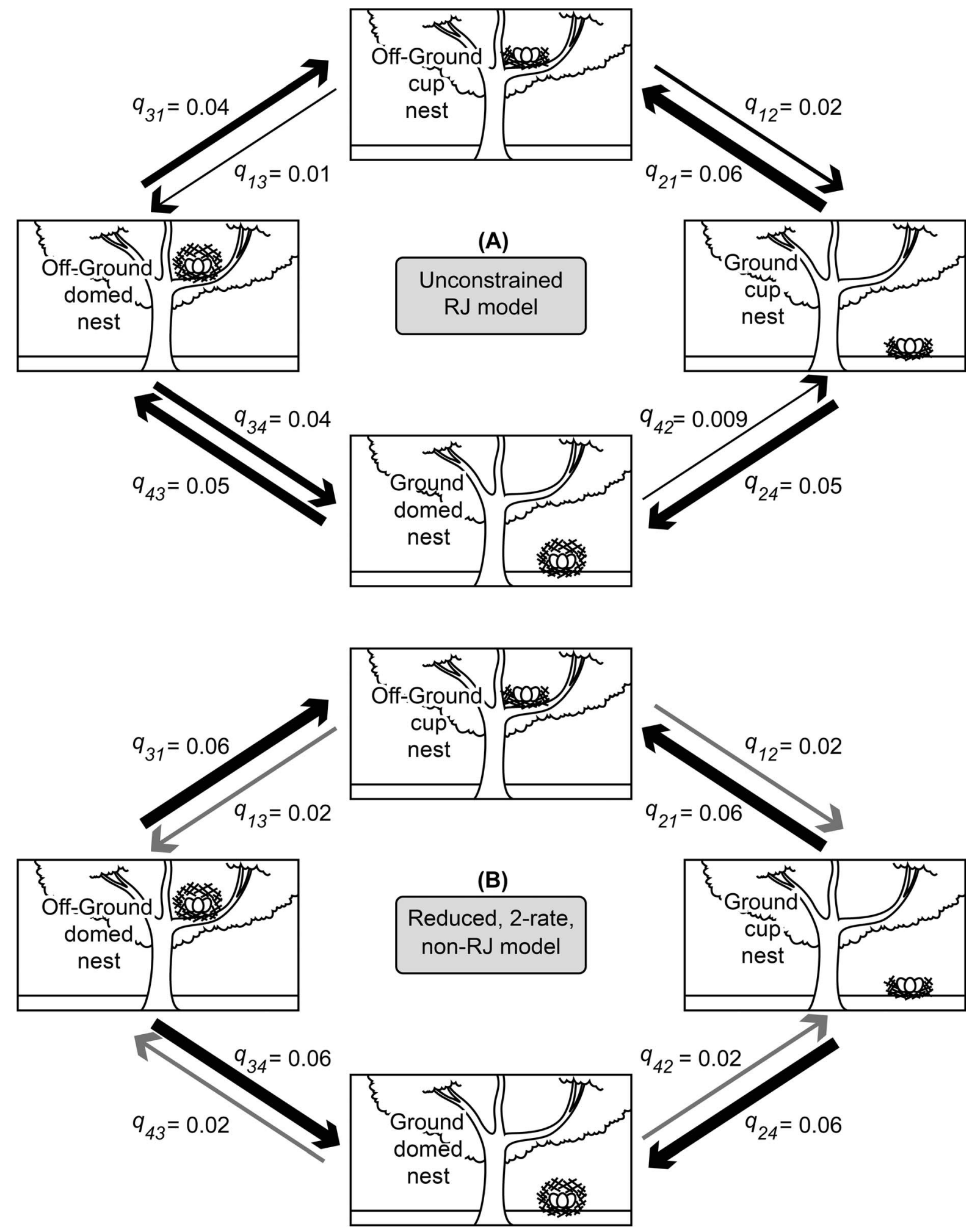

FIGURE 3. Two transition rate models used to investigate the coevolution of nest height and nest structure in Timaliidae. (A) An unconstrained, dependent reversible jump (RJ) model used to estimate 8 evolutionary transition rates $(q)$ corresponding to all possible transitions between nest height and nest structure state combinations. (B) A reduced, dependent non-RJ model of nest structure and nest height in which only 2 transition rates were estimated: transitions toward nest states predicted to be favorable (black arrows; toward off-ground cup nest and ground domed nest; $q_{34}, q_{24}, q_{21}$, and $q_{31}$ ), and transitions away from nest states predicted to be favorable (gray arrows; $q_{12}, q_{13}, q_{43}$, and $q_{42}$ ). Arrow thickness is proportional to the likelihood of the associated transition. These analyses incorporated phylogenetic relatedness from the Jetz et al. (2012) phylogenies. 
estimated to test the predictions that transitions in nest structure depended on nest height and vice versa.

In addition to the RJ model of dependent evolution, we ran a simpler, non-RJ model of dependent evolution in which only the transition rates of direct relevance to the coevolutionary hypothesis were allowed to vary. In the reduced dependent model (Figure 3B), 2 transition rates were estimated, 1 corresponding to state transitions that we predicted would not be evolutionarily favored (i.e. toward building a cup nest on the ground and building a domed nest off the ground; in Figure 3B: $q_{12}=q_{13}=q_{43}=$ $\left.q_{42}\right)$, and 1 corresponding to state transitions that we predicted would be evolutionarily favored (i.e. toward building a cup nest off the ground and building a domed nest on the ground; in Figure 3B: $q_{34}=q_{24}=q_{21}=q_{31}$ ). We predicted that the former rate would be smaller than the latter rate, suggesting that building a cup nest coevolved with building off the ground and building a domed nest coevolved with building on the ground, as hypothesized by Collias (1997). We compared this reduced, non-RJ, 2-rate model to a reduced, non-RJ, 1-rate model in which all state transition rates were held equal, corresponding to independent evolution of the traits (not shown).

Ancestral states. To investigate the most likely ancestral states of nest structure and nest height in Timaliidae, we compared models in which the most recent common ancestor was fixed as (1) building a cup nest off the ground (the predicted ancestral state), (2) building a cup nest on the ground, (3) building a domed nest off the ground, or (4) building a domed nest on the ground (the predicted derived state). We compared ancestral states models using both the full, dependent RJ model, and the reduced, nonRJ, 2-rate dependent model used above in our coevolutionary analyses.

Order of evolutionary transitions. We investigated the likely order of evolutionary transitions by testing whether transitions from the predicted ancestral state of building a cup nest off the ground to building a domed nest on the ground were more or less likely to occur first through changes in nest height or nest structure (i.e. whether $q_{12} \neq$ $\left.q_{13}\right)$. We also tested whether transitions from the predicted derived state of building a domed nest on the ground to building a cup nest off the ground were more or less likely to occur first through changes in nest height or nest structure (i.e. whether $q_{43} \neq q_{42}$; Pagel 1997). We compared RJ dependent models, in which the 2 rates of interest were fixed as equal (in which changes in nest structure and height were equally likely), to unconstrained RJ dependent models, with the prediction that, if the transition rates of interest differed strongly, the unconstrained models should be supported over the restricted models. We did not perform order of evolutionary transitions analyses on our reduced 2-rate model of dependent evolution (Figure $3 \mathrm{~B}$ ) because transition rates
TABLE 1. Bayes Factor ranges and associated interpretations used in comparative analyses in this study. Values and interpretations were taken from Pagel et al. (2004).

\begin{tabular}{ll}
\hline $\begin{array}{l}\text { Log Bayes } \\
\text { Factor }\end{array}$ & \multicolumn{1}{c}{ Interpretation } \\
\hline $0-2$ & Weak evidence for hypothesized relationship \\
$2-5$ & Positive evidence for hypothesized relationship \\
$5-10$ & Strong evidence for hypothesized relationship \\
\hline
\end{tabular}

of interest in this model were fixed as equal (see above) and could not be compared.

Model diagnostics and comparison. For all analyses, we ran $3 \mathrm{MCMC}$ chains to ensure that chains converged on similar values. All reported model parameters were averaged across the 3 chains. The program Tracer (Rambaut and Drummond 2007) was used for visual examination of chains to ensure convergence and to estimate effective sample size (ESS) for posterior probability distributions. No analysis reported an ESS below $\sim 2,000$ for model parameters (apart from one problematic analysis, detailed in the Results). We used Bayes Factors (BF) to compare model fit based on the harmonic means of the model likelihoods, where, by convention, a positive value of $>2$ is taken as 'positive evidence' and $5-10$ as 'strong evidence' for the better-fitting model (Table 1; Pagel et al. 2004). Harmonic means were taken as the final iteration in the MCMC chain.

\section{RESULTS}

\section{Nest Heights of Domed- vs. Cup-Nesters}

Babbler species that built domed nests built closer to the ground than did the species that built cup nests, regardless of whether analyses were based on the Jetz et al. (2012) phylogenies (99\% $\beta<0, \lambda=0.64, n=97$; Figure 4) or the Moyle et al. (2012) phylogenies (98\% $\beta<0, \lambda=0.63, n=$ 91).

\section{Coevolution of Nest Height and Nest Structure}

Nest structure and nest height coevolved in Timaliidae, which suggests that transitions in nest height depended on nest structure and vice versa, rather than evolving independently of one another, for analyses based both on the Jetz et al. (2012) phylogenies $(\mathrm{BF}=4.0$ in favor of our unconstrained RJ dependent model, $n=97)$ and the Moyle et al. (2012) phylogenies ( $B F=7.3$ in favor of our unconstrained RJ dependent model, $n=91$ ).

Building a cup nest coevolved with building off the ground and building a domed nest coevolved with building on the ground: Our reduced, non-RJ, 2-rate model of dependent evolution between nest height and nest structure was strongly favored over a reduced, non-RJ, 1rate model of independent evolution of these 2 nest traits, 


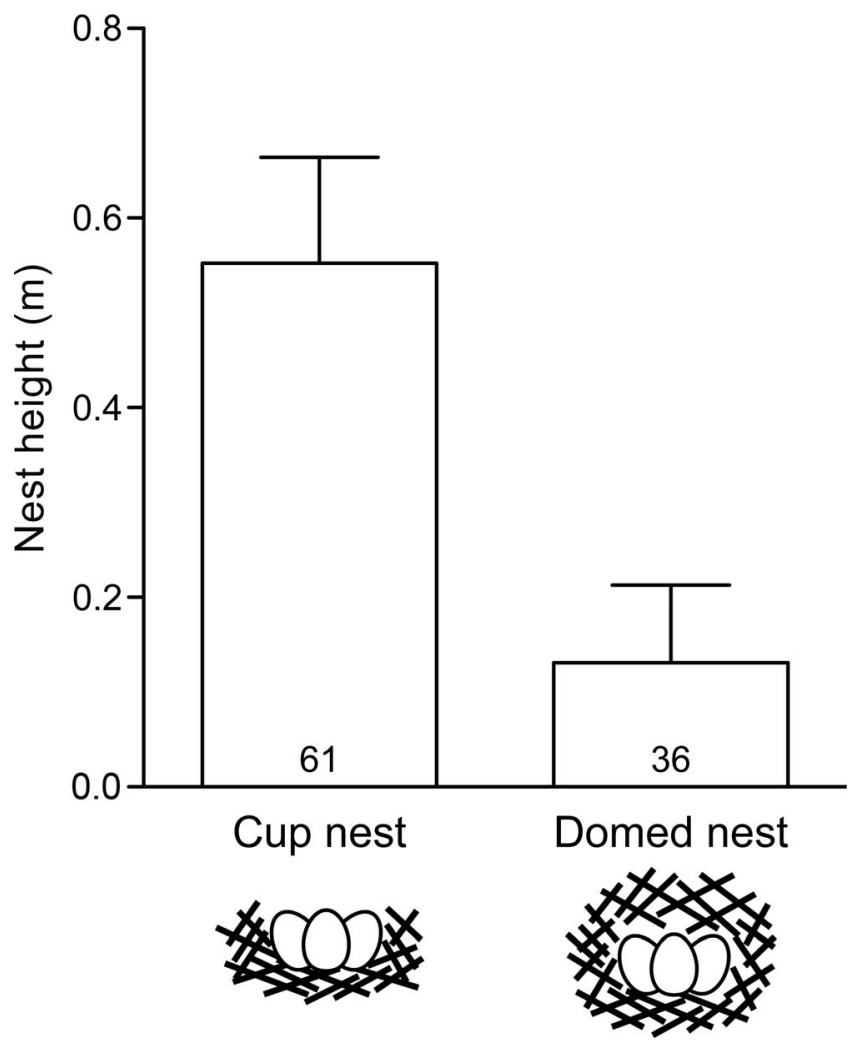

FIGURE 4. Species in Timaliidae that build domed nests build their nests at lower heights than do their cup-nest-building relatives. Bars represent average nest heights + SEM (standard error of the mean) of cup- and domed-nest species in Timaliidae prior to transformation and statistical analyses. The number within each bar represents the sample size for each nest structure group. These analyses incorporated phylogenetic relatedness from the Jetz et al. (2012) phylogenies.

for analyses based both on the Jetz et al. (2012) phylogenies $(\mathrm{BF}=9.0, n=97)$ and the Moyle et al. (2012) phylogenies $(\mathrm{BF}=7.1, n=91)$.

In analyses based on either phylogeny reconstruction, mean estimated transition rates from the favoured RJ dependent model supported the dependent evolution of nest structure on nest height. Namely, transitions from cup to domed nests were more likely in ground nest than offground nest-building lineages $\left(q_{13}<q_{24}\right)$, and transitions from domed to cup nests were more likely in off-ground than ground nest builders $\left(q_{42}<q_{31}\right)$. Changes in nest height, however, did not clearly depend on nest structure: Compared with transitions in nest structure, transitions between off-ground and ground nest building were fairly similar regardless of nest structure, for analyses based on either tree sample. These changes were in the predicted direction (in which transitions from off-ground to ground nest building are more likely in domed nest-building species $\left[q_{12}<q_{34}\right]$ and transitions from ground to offground nest building are more likely in cup nest-building species $\left.\left[q_{43}<q_{21}\right]\right)$ for analyses based on the Jetz et al. (2012) trees only.

In the favored non-RJ, 2-rate model of dependent evolution, transitions toward building cup nests and building off the ground and toward building domed nests and building on the ground were more likely than were transitions away from these 2 state combinations (i.e. in Figure 3B: $q_{12}<q_{34}, q_{13}<q_{24}, q_{43}<q_{21}$, and $q_{42}<q_{31}$ ), regardless of which trees were used in the analyses.

\section{Ancestral States}

The building of a cup nest coupled with building that nest off the ground was more likely to be the ancestral state in Timaliidae than was building a domed nest on the ground, regardless of which model of evolution was employed (unconstrained RJ dependent model or reduced 2-rate, non-RJ dependent model) or which trees were used in the analyses (BFs > 3.8). Building a domed nest on the ground was also the less likely ancestral state compared with building a cup nest on the ground and building a domed nest off the ground, regardless of evolutionary model or phylogeny employed (BFs > 2.0). However, we did not find sufficient statistical evidence that building a cup nest off the ground was the more likely ancestral state compared with building a cup nest on the ground or building a domed nest off the ground (see Supplementary Material Table S2.3).

\section{Order of Evolutionary Transitions}

We did not find clear evidence as to whether transitions from building cup nests off the ground to building domed nests on the ground were more likely to occur first through changes in nest height or in nest structure. For analyses based on both tree samples, transition rates from the unconstrained RJ dependent model suggested that from building a cup nest off the ground, changes in nest height were more likely than changes in nest structure (i.e. in Figure 3A: $\left.q_{12}>q_{13}\right)$. However, restricting $q_{12}=q_{13}$ reduced model fit relative only to the unconstrained RJ model for analyses based on the Moyle et al. (2012) trees $(\mathrm{BF}=-6.0)$, whereas it improved model fit for analyses based on the Jetz et al. (2012) trees $(B F=3.0)$. Similarly, transition rates from the unconstrained $\mathrm{RJ}$ dependent model suggested that transitions away from the probable derived state of building a domed nest and building on the ground were more likely to occur first via changes in nest height rather than in nest structure (i.e. in Figure 3A: $q_{43}>$ $q_{42}$ ). Fixing these two transition rates to be equal reduced the model fit relative to the unconstrained model for the analyses based both on the Jetz et al. $(2012 ; \mathrm{BF}=-4.2)$ and on the Moyle et al. (2012; BF $=-5.6)$ tree samples. However, unlike all other analyses, MCMC chains for models in which rates $q_{43}$ and $q_{42}$ were fixed as equal based on the Moyle et al. (2012) tree performed poorly, 
producing low effective sample sizes (minimum $\sim 60$ ), despite running additional chains of up to a billion iterations with sparser sampling (every 50,000 iterations). This particular result should, therefore, be interpreted with caution.

\section{DISCUSSION}

Taken together, we have shown that those lineages of Old World babblers that add a dome to their nests build their nests at a lower height than do related species that build cup nests. Building a domed nest and building that nest on the ground coevolved, probably as derived traits, as predicted by Collias (1997). This is the first direct evidence that nest height can influence the evolution of nest structure; specifically, in this case, that the evolution of domed nests depends on building nests on the ground, while the evolution of cup nests depends on building nests off the ground.

These are the first phylogenetic comparative analyses to support the idea that building a cup nest off the ground or a domed nest on the ground are favored by selection, while building either domed nests off the ground or cup nests on the ground are not, at least in Timaliidae (Collias and Collias 1984). This coevolution of nest height and structure also supports the prediction of Collias (1997) that the susceptibility of open-cup nests built near the ground to predation may influence the evolution of nest height and structure. Increased predation pressure near the ground from introduced terrestrial mammals also seems to explain the change in nest elevation in other bird families; for example, a Hawaiian monarch flycatcher (the Oahu Elepaio [Chasiempis ibidis]) now constructs its cup nest 50\% higher than was reported in 1995 (Vanderwerf 2012), following the introduction of terrestrial predators. A general increase in nest height in cup-nesting species in response to changing predation pressure, as predicted by Collias (1997), is not necessarily to be expected, however, as pointed out by Newmark and Stanley (2011). Rather, the effect of nest height on nest predation is likely to be species-specific and influenced by the importance of predators operating at different heights in different habitats. Domes on nests do appear to reduce predation risk: Eggs in ovenbird nests with artificial domes were less susceptible to predation than were eggs placed in artificial cup nests when both nest types were placed on the ground (Linder and Bollinger 1995). Determining the mechanism through which this protection is conferred, which could include factors such as accessibility to incubating birds and young and nest camouflage, requires further investigation.

Without directly testing the influences of predation or nest-site competition, we cannot discount alternative selection pressures that may have driven the evolutionary transitions that we identified. For example, if Timaliidae nests built on the ground are exposed to less sunlight than nests built off the ground, then domed nests may help to maintain a thermal environment in the nest comparable with a cup nest off the ground that is exposed to more sunlight. The role of such alternative selection pressures on nest structure in the Timaliidae (and in other species) also requires further investigation.

Building a domed nest on the ground is unlikely to have been the ancestral state in Timaliidae. Consistent with this result, Old World warblers (Sylviidae), which are considered to be close relatives of the Timaliids, typically build cup-shaped nests off the ground (Perrins 1991). This result also concurs with the predictions of Collias (1997) that a cup nest built off the ground is likely to have been the ancestral state in Timaliidae, and that adding a dome to a nest and building on the ground coevolved as derived traits.

Collias (1997) argued that, from the proposed ancestral state of building a cup nest off the ground, evolutionary transitions to building a domed nest would not be favored compared with transitions to building a nest on the ground, because building a nest off the ground should already confer protection from ground predators and birds should avoid the presumed higher energetic cost incurred by the additional effort of creating a nest roof (Bailey et al. 2014). In support of Collias' (1997) prediction, we found that building a domed nest and building this nest off the ground was not an evolutionarily favored state combination compared with building a cup nest off the ground or a domed nest on the ground. Furthermore, our results suggested that evolutionary transitions away from building cup nests off the ground were more likely to occur first as transitions to building nests on the ground than to building domed nests. It should be noted that this result was strongly supported only with the family-specific phylogeny taken from Moyle et al. (2012). Compared with the Jetz et al. (2012) phylogenies, this family-specific phylogeny included more species of Timaliidae and was constructed using only genetic data, suggesting that while the Jetz et al. (2012) sample is more appropriate for broader comparative analyses extending beyond single families, the Moyle et al. (2012) tree is a potentially more robust phylogenetic reconstruction on which to base family-specific comparative analyses such as these. Crucially, more representative species sampling in the Moyle et al. (2012) tree may have resulted in the identification of a greater number of multiple independent character state transitions, which are critical for testing coevolutionary hypotheses using phylogenetic comparative analyses.

Although we found evidence that transitions from building a cup nest off the ground were more likely to occur first as a change in nest height, we found that transitions first to building a domed nest off the ground were possible, just at a lower probability than a transition 
first to building a ground nest. One alternative explanation as to why babblers might evolve from building cup nests off the ground to building domed nests off the ground was also proposed by Collias (1997): Building domed nests may be favored in species that build their nests in the canopy periphery because an enclosed nest may mitigate the effects of increased exposure to adverse weather experienced by nests placed farther away from the tree trunk. Data regarding the location of nests within off-ground nest sites such as trees and the benefits of such locations are required, however, to test this hypothesis.

Finally, our results suggested that from the probable derived state of building domed nests on the ground, transitions in nest height were more likely than transitions in nest structure. Changes in nest height occurring before changes in nest structure, more generally, would be consistent with reports on phenotypic plasticity in nest height (Vanderwerf 2012) and suggest that species in the Timaliidae that build domed nests on the ground are more likely to respond to environmental threats, such as increased nest predation, by changing the height at which they build their nests before changing the structure of the nests that they build. Unfortunately, however, we were unable to draw firm conclusions about the strength of this contrast in transition rates for analyses based on the Moyle et al. (2012) trees due to poor chain performance in this specific analysis. Therefore, while our analyses show robust support for the coevolution of nest height and nest structure in the babblers, the specific evolutionary pathways by which nest height and structure coevolve remain to be investigated further.

In sum, here we present the first formal analyses of coevolution between nest height and nest structure and show that babblers that evolved to build their nests on the ground consequently evolved to construct roofs on their nests, suggesting that changes in nest design have occurred in response to selection by ecological pressures. These coevolutionary analyses demonstrate how accumulated descriptions of nest structure and phylogenetically informed statistics can help to elucidate the evolutionary history of a long-observed but surprisingly still mysterious behavior, nest building.

\section{ACKNOWLEDGMENTS}

We thank Chris Venditti for advice regarding statistical analysis and Chris, David Shuker, and three anonymous reviewers for helpful comments on earlier versions of the manuscript. We thank Robert Moyle for kindly providing an ultrametric version of the phylogeny suitable for use in our comparative analyses.

Funding statement. This work was supported by the Biotechnology and Biological Sciences Research Council (grant number BB/I019502/1 to S.D.H.), The Natural Sciences and Engineering Research Council of Canada (grant number PGSD3-409582-2011 to Z.J.H.), and the European Research Council (grant number 232823 to S.E.S.). None of the funders had any input into the content of the manuscript. None of the funders were required to provide approval of the manuscript before submission or publication.

\section{LITERATURE CITED}

Bailey, I. E., K. V. Morgan, M. Bertin, S. L. Meddle, and S. D. Healy (2014). Physical cognition: Birds learn the structural efficacy of nest material. Proceedings of the Royal Society of London, Series B 281:20133225. doi:10.1098/rspb.2013.3225

Collar, N. J., and C. Robson (2007). Family Timaliidae (Babblers). In Handbook of the Birds of the World, Volume 12: Picathartes to Tits and Chickadees (J. del Hoyo, A. Elliott, and J. Sargatal, Editors), Lynx Editions, Barcelona, pp. 70-291.

Collias, N. E. (1997). On the origin and evolution of nest building by passerine birds. The Condor 99:253-270.

Collias, N. E., and E. C. Collias (1984). Nest Building and Bird Behavior. Princeton University Press, Princeton, NJ, USA.

Deeming, D. C., M. C. Mainwaring, I. R. Hartley, and S. J. Reynolds (2012). Local temperature and not latitude determines the design of Blue Tit and Great Tit nests. Avian Biology Research 5:203-208.

Eberhard, J. R. (1998). Evolution of nest-building behavior in Agapornis parrots. The Auk 115:455-464.

Grafen, A. (1989). The phylogenetic regression. Philosophical Transactions of the Royal Society of London, Series B 326: 119-157.

Hackett, S. J., R. T. Kimball, S. Reddy, R. C. K. Bowie, E. L. Braun, M. J. Braun, J. L. Chojnowski, W. A. Cox, K. Han, J. Harshman, C. J. Huddleston, et al. (2008). A phylogenomic study of birds reveals their evolutionary history. Science 320:1763-1768.

Hall, Z. J., M. Bertin, I. E. Bailey, S. L. Meddle, and S. D. Healy (2014). Neural correlates of nesting behavior in Zebra Finches (Taeniopygia guttata). Behavioural Brain Research 264:26-33.

Hall, Z. J., S. E. Street, and S. D. Healy (2013). The evolution of cerebellum structure correlates with nest complexity. Biology Letters 9:20130687. doi:10.1098/rsbl.2013.0687

Heenan, C. B., and R. S. Seymour (2011). Structural support, not insulation, is the primary driver for avian cup-shaped nest design. Proceedings of the Royal Society of London, Series B 278:2924-2929.

Heenan, C. B., and R. S. Seymour (2012). The effect of wind on the rate of heat loss from avian cup-shaped nests. PLOS One 7:e32252. doi:10.1371/journal.pone.0032252

Hoi, H., A. Krištín, F. Valera, and C. Hoi (2012). Traditional versus non-traditional nest-site choice: Alternative decision strategies for nest-site selection. Oecologia 169:117-124.

Irestedt, M., J. Fjeldså, and P. G. P. Ericson (2006). Evolution of the ovenbird-woodcreeper assemblage (Aves: Furnariidae)_ Major shifts in nest architecture and adaptive radiation. Journal of Avian Biology 37:260-272.

Jetz, W., G. H. Thomas, J. B. Joy, K. Hartmann, and A. O. Mooers (2012). The global diversity of birds in space and time. Nature 491:444-448.

Kipling, R. (1899). The Jungle Book. Macmillan, London, UK.

Linder, E. T., and E. K. Bollinger (1995). Depredation of artificial Ovenbird nests in a forest patch. Wilson Bulletin 107:169-174. 
Mainwaring, M. C., D. C. Deeming, C. I. Jones, and I. R. Hartley (2014). Adaptive latitudinal variation in Common Blackbird Turdus merula nest characteristics. Ecology and Evolution 4: 841-851.

Marzluff, J. M. (1998). Do Pinyon Jays alter nest placement based on prior experience? Animal Behaviour 36:1-10.

Moyle, R. G., M. J. Andersen, C. H. Oliveros, F. D. Steinheimer, and S. Reddy (2012). Phylogeny and biogeography of the core babblers (Aves: Timaliidae). Systematic Biology 61:631-651.

Muth, F., and S. D. Healy (2011). The role of adult experience in nest building in the Zebra Finch, Taeniopygia guttata. Animal Behaviour 82:185-189.

Muth, F., and S. D. Healy (2012). Zebra Finches build nests that do not resemble their natal nest. Avian Biology Research 5: 218-226.

Muth, F., and S. D. Healy (2014). Zebra Finches select nest material appropriate for a building task. Animal Behaviour 90: 237-244.

Muth, F., M. Steele, and S. D. Healy (2013). Colour preferences in nest-building Zebra Finches. Behavioural Processes 99:106111.

Newmark, W. D., and T. R. Stanley (2011). Habitat fragmentation reduces nest survival in an Afrotropical bird community in a biodiversity hotspot. Proceedings of the National Academy of Sciences USA 108:11488-11493.
Pagel, M. (1997). Inferring evolutionary processes from phylogenies. Zoologica Scripta 26:331-348.

Pagel, M., and A. Meade (2006). Bayesian analysis of correlated evolution of discrete characters by reversible-jump Markov chain Monte Carlo. American Naturalist 167:808-825.

Pagel, M., A. Meade, and D. Barker (2004). Bayesian estimation of ancestral character states on phylogenies. Systematic Biology 53:673-684.

Perrins, C. (1991). Sylviidae. In Encyclopedia of Animals: Birds (J. Forshaw, Editor), Merehurst Press, London, UK, pp. 192-194.

Rambaut, A., and A. J. Drummond (2007). Tracer. http://beast. bio.ed.ac.uk/Tracer

Ross, C. F., J. Iriarte-Diaz, and C. L. Nunn (2012). Innovative approaches to the relationship between diet and mandibular morphology in primates. International Journal of Primatology 33:632-660.

Vanderwerf, E. A. (2012). Evolution of nesting height in an endangered Hawaiian forest bird in response to a non-native predator. Conservation Biology 26:905-911.

Winkler, D. W., and F. H. Sheldon (1993). Evolution of nest construction in swallows (Hirundinidae): A molecular phylogenetic perspective. Proceedings of the National Academy of Sciences USA 90:5705-5707. 